\title{
PERANAN PAJAK BUMI DAN BANGUNAN PERDESAAN DAN PERKOTAAN MELALUI EFEKTIVITAS DAN KONTRIBUSI TERHADAP PENDAPATAN ASLI DAERAH KABUPATEN SITUBONDO
}

\author{
Mu'min Al-Mukhlisin ${ }^{1)}$, Galih Wicaksono ${ }^{2)^{*}}$, Venantya Asmandani ${ }^{3)}$ \\ 1) mukhlishinalmukmin@gmail.com, Universitas Jember \\ 2) galih.fisip@unej.ac.id, Universitas Jember* \\ 3)vena.mandani@unej.ac.id, Universitas Jember \\ *penulis korespondensi
}

\begin{abstract}
This research is aimed at knowing the role of the Earth Tax and Rural and Urban Buildings (UN-P2) through its effectiveness and contribution to Regional Original Income (PAD) in Situbondo Regency. The study used descriptive quantitative methods. The type of data used is secondary data obtained from the Situbondo District Data Center Application. The data used is the target and realization of UN-P2 acceptance, the realization of PAD receipts in Situbondo Regency during 2018-2020. The results showed that the effectiveness of UN-P2 from year to year is still ineffective. While the contribution of $U N-P 2$ to PAD is still very lacking every year. So that in the future so that the role of UN-P2 on PAD can be optimal, the Situbondo Regency Government needs to explore the potentials in the form of Earth Tax objects and Rural and Urban Buildings and conduct intensive tax socialization to improve UN P2 compliance on time with the appropriate amount .
\end{abstract}

Keywords : Role, Effectiveness, Contribution, $P B B-P 2, P A D$

\begin{abstract}
Abstrak
Untuk memperkuat esensi dan posisi otonomi dalam menopang kapasitas fiskal daerah, pemerintah pusat memberikan wewenang kepada pemerintah daerah atas pungutan pajak daerah dan retribusi daerah sesuai dengan amanat Undang-Undang Nomor 28 Tahun 2009 tentang Pajak Daerah dan Retribusi Daerah. Penelitian ini ditujukan untuk mengetahui peranan Pajak Bumi dan Bangunan Perdesaan dan Perkotaan (PBB-P2) melalui efektivitas dan kontribusinya terhadap Pendapatan Asli Daerah (PAD) di Kabupaten Situbondo. Penelitian ini menggunakan metode kuantitatif deskriptif. Jenis data yang digunakan adalah data sekunder yang diperoleh dari Aplikasi Pusat Data Kabupaten Situbondo. Data yang digunakan adalah target dan realisasi penerimaan PBB-P2, realisasi penerimaan PAD di Kabupaten Situbondo selama tahun 2018-2020. Hasil penelitian menunjukan bahwa efektivitas PBB-P2 dari tahun ke tahun masih tidak efektif. Sedangkan kontribusi PBB-P2 terhadap PAD masih sangat kurang pada setiap tahunnya. Sehingga ke depannya agar peran PBB-P2 terhadap PAD dapat optimal, Pemerintah Kabupaten Situbondo perlu menggali potensi-potensi berupa obyek Pajak Bumi dan Bangunan Pedesaaan dan Perkotaan dan mengadakan sosialisasi perpajakan secara intensif untuk meningkatkan kepatuhan PBB P2 tepat waktu dengan jumlah yang sesuai.
\end{abstract}

Kata kunci : Peranan, Efektivitas, Kontribusi, PBB-P2, PAD

\section{PENDAHULUAN}

Berdasarkan Undang-Undang Nomor 28 Tahun 2007 tentang Ketentuan Umum dan Tatacara Perpajakan, pajak adalah kontribusi wajib kepada negara yang terutang oleh orang pribadi atau badan yang bersifat memaksa berdasarkan undang-undang, dengan tidak mendapatkan imbalan secara langsung dan digunakan untuk keperluan negara bagi sebesarbesarnya kemakmuran rakyat. Pajak dikelola langsung oleh pemerintah untuk pengeluaran umum serta pembangunan demi memberikan kesejahteraan serta kemakmuran kepada rakyatnya. Tidak hanya pemerintah pusat saja yang mempunyai wewenang untuk memungut pajak, akan tetapi pemerintah daerah juga mempunyai wewenang untuk memungut Pajak Daerah dan Retribusi Daerah (PDRD). Seperti yang tercantum pada Peraturan Daerah 
Kabupaten Situbondo tentang Pajak Daerah bahwa pajak daerah adalah kontribusi wajib pajak kepada daerah yang terutang oleh orang pribadi atau badan yang bersifat memaksa berdasarkan Undang-undang dengan tidak mendapatkan timbal balik secara langsung dan digunakan untuk pembangunan daerah demi kesejahteraan rakyat.

Keberhasilan suatu bangsa dalam pembangunan nasional sangat ditentukan oleh kemampuan bangsa untuk memajukan masyarakat maka diperlukan dana untuk pembiayaan pembangunan guna mencapai tujuan yang diinginkan. Usaha untuk mencapai tujuan tersebut salah satunya adalah melalui pajak. Pajak merupakan iuran kepada kas negara berdasarkan undang-undang yang dapat dipaksakan dengan tidak mendapat jasa timbal (kontrapestasi), yang berlangsung dapat ditujukan dan digunakan untuk membayar pengeluaran umum (Waluyo, 2013). Menurut Boedijono dkk (2019), pemerintahan memiliki peran dalam pengelolaan keuangan publik, yang dimulai dari tata kelola keuangan pusat, daerah, maupun desa. Menurut Asmandani dkk (2020) menyatakan bahwa penerimaan terbesar berasal dari pajak.

Berdasarkan UU No.28 Tahun 2009 tentang Pajak Daerah dan Retribusi Daerah, pemerintah daerah diberikan wewenang untuk melakukan pemungutan pajak daerah di suatu daerah sesuai dengan potensi dan kebijakan daerah yang ditetapkan dengan Peraturan Daerah (Perda). Salah satu jenis pajak daerah yang wewenang pemungutannya diberikan ke pemerintah daerah adalah Pajak Bumi dan Bangunan Perdesaan dan Perkotaan (PBB-P2). Pajak Bumi dan Bangunan (PBB) adalah pajak yang dipungut atas tanah dan bangunan karena adanya keuntungan dan kedudukan sosial ekonomi yang lebih baik bagi orang atau badan yang mempunyai hak atas manfaat bumi dan atau bangunan tersebut. Dasar pengenaan PBB adalah nilai jual objek pajak (NJOP). NJOP ditentukan berdasarkan harga pasar per wilayah dan ditetapkan setiap tahun oleh menteri keuangan bersama dengan pemerintah daerah kabupaten/kota. PBB memiliki peran yang cukup besar bagi kelangsungan dan kelancaran pembangunan, sehingga perlu ditangani dan dikelola lebih intensif (Suparmono, 2010).

Sektor penerimaan dari PBB-P2 dialihkan kepada pemerintah daerah untuk memberikan wewenang kepada pemerintah daerah untuk memperluas pajak daerah, menetapkan tarif pajak daerah, dan menetapkan fungsi pajak sebagai anggaran daerah. Wewenang perpajakan ini diberikan kepada pemerintah daerah yang diharapkan mampu menjadi salah satu sumber Pendapatan Asli Daerah (PAD) yang potensial bagi suatu daerah. Pemerintah daerah harus menetapkan target dalam penerimaan PBB-P2 sebagai salah satu pendapatan potensial daerah, namun realisasi yang diharapkan terkadang tidak sesuai dengan target dan rencana yang sudah ditetapkan oleh pemerintah daerah.

Kabupaten Situbondo adalah salah satu kabupaten di wilayah Provinsi Jawa Timur yang sudah menerapkan PBB-P2 sebagai salah satu pajak daerah sejak tahun 2014. Hal tersebut dilakukan untuk menindaklanjuti Undang-undang Nomor 28 Tahun 2009 tentang Pajak Daerah dan Retribusi Daerah, yang mengamanatkan kepada pemerintah kabupaten/kota untuk mengelola sendiri PBB-P2. Untuk memaksimalkan penerimaan PAD di Kabupaten Situbondo, maka Pemerintah Kabupaten Situbondo harus memiliki strategi untuk merealisasikan target PBB-P2 agar sesuai dengan target yang sudah ditentukan.

Kajian mengenai peranan PBB-P2 terhadap PAD melalui efektivitas penerimaan PBBP2 dirasa sangat penting, karena dengan adanya kajian tersebut akan diperoleh gambaran seberapa besar efektivitas penerimaan PBB-P2 pada suatu tahun. Selain itu juga untuk menegtahui peranan terhadap PAD, perlu dihitung seberapa besar kontribusi penerimaan PBBP2 terhadap PAD. Apabila dirasa kurang maka perlu mencari strategi yang tepat dalam menggali potensi yang ada, sehingga penerimaan PBB-P2 memberi kontribusi yang optimal bagi PAD di Kabupaten Situbondo. Sejalan dengan hal tersebut, efektivitas penerimaan PBB P-2 telah dilakukan kajian. Wicaksono dan Pamungkas (2017) telah menganlisis efektivitas PBB P-2 terhadap Pendapatan Asli Daerah di Kota Jember dengan hasil yaitu tingkat efektivitas 
PBB P2 pada tahun 2013 berada dalam kategori cukup efektif, sedangkan pada tahun 2014 dan 2015 berada dalam kategori kurang efektif. Untuk tingkat kontribusi PBB P2 terhadap Pendapatan Asli Daerah (PAD), menunjukkan bahwa pada tahun 2013-2015 tingkat kontribusi berada dalam kategori sangat kurang.

Damaiyanti dan Setiawan (2014) juga telah melakukan analisis tentang efektivitas dan kontribusi PBB P-2 terhadap PAD di Kota Denpasar, dengan hasil efektivitas penerimaan Pajak Bumi dan Bangunan tahun 2009-2013 sangat efektif dengan rata-rata diatas 100\%, yaitu 121,42\%. Kontribusi penerimaan Pajak Bumi dan Bangunan terhadap Pendapatan Asli Daerah menunjukkan hasil kurang dengan rata-rata dibawah $50 \%$, yaitu $18,62 \%$. Selain itu, Wardani dan Fadhlia (2017) dengan hasil yaitu efektivitas penerimaan pajak bumi dan bangunan perdesaan dan perkotaan di Kabupaten Aceh Besar mengalami peningkatan setiap tahunnya dengan rata-rata presentase sebesar $100.10 \%$. Kontribusi pajak bumi dan bangunan perdesaan dan perkotaan di Kabupaten Aceh Besar dikategorikan sangat kurang, dimana rata-rata persentase hanya $2.08 \%$. Dari beberapa peneliti yang telah dijelaskan di atas, maka efektivitas PBB P-2 mempengaruhi PAD dan dapat memberikan kontribusi terhadap PAD.

Adapun Huda dan Wicaksono (2021) meneliti efektivitas dan kontribusi PBB P-2 di Kota Yogyakarta dengan hasil penerimaan PBB-P2 mengalami pertumbuhan di setiap tahunnya, walaupun target penerimaan di setiap tahunnya selalu sama. Untuk efektivitas, menghasilkan temuan bahwa penerimaan PBB-P2 setiap tahunnya berada pada kategori sangat efektif, hal ini dikarenakan nilai realisasi selalu lebih besar dibandingkan dengan target yang ditetapkan. Untuk kontribusi terhadap PAD, menghasilkan temuan bahwa penerimaan PBB-P2 berada pada kategori kurang kontribusinya, sehingga untuk ke depannya perlu ditingkatkan lagi besaran target dan realisasinya, sehingga menghasilkan kontribusi yang optimal.

Dari beberapa penelitian terdahulu yang telah dijelaskan sebelumnya, maka perbedaan penelitian terdahulu dengan penelitian ini, yaitu penelitian saat ini berfokus untuk menganalisis peranan PBB P-2 dan mengetahui seberapa efektif penerimaan PBB P-2 terhadap PAD di Kabupaten Situbondo selama 3 tahun yaitu dari tahun 2018 sampai dengan tahun 2020. Berdasarkan penjelasan latar belakang, maka tujuan dari penelitian ini adalah untuk mengetahui peranan Pajak Bumi dan Bangunan Perdesaan dan Perkotaan melalui efektivitas dan kontribusinya terhadap Pendapatan Asli Daerah di Kabupaten Situbondo.

\section{KAJIAN PUSTAKA Peranan}

Menurut Soekanto (2012) peranan merupakan aspek dinamis kedudukan (status). Apabila seseorang melaksankan hak dan kewajibannya sesuai dengan kedudukannya, maka ia menjalankan suatu peranan.

\section{Efektivitas}

Mardiasmo (2009) menyatakan bahwa efektivitas digunakan untuk mengukur berhasil tidaknya organisasi dalam mencapai tujuannya.. Efektivitas juga bisa menunjukkan taraf tercapainya tujuan, usaha dikatakan efektiv kalau usaha itu mencapai sudah mencapai tujuan.

\section{Kontribusi}

Menurut Guritno (1997), Kontribusi adalah suatu yang diberikan bersama-sama dengan pihak lain untuk tujuan biaya atau kerugian tertentu atau bersama. Sehingga kontribusi yang dimaksud dapat diartikan sebagai sumbangan yang diberikan oleh penerimaan pajak bumi dan bangunan perdesaan dan perkotaan dalam pendapatan asli daerah.

Pajak Bumi dan Bangunan Perdesaan dan Perkotaan (PBB-P2)

Berdasarkan Undang-undang No. 28 tahun 2009 tentang Pajak Daerah dan Retribusi Daerah, PBB-P2 adalah pajak atas bumi dan/atau bangunan yang dimiliki, dikuasai, dan/atau dimanfaatkan oleh orang pribadi atau badan, kecuali kawasan yang digunakan untuk kegiatan 
usaha perhutanan, perkebunan, dan pertambangan. Objek pajak bumi yang diatur di dalam peraturan ini yaitu terdiri dari permukaan bumi dan tubuh bumi (Mustofa \& Usman, 2021). Bumi adalah permukaan bumi yang meliputi tanah dan perairan pedalaman serta laut wilayah kabupaten/kota. Bangunan adalah konstruksi teknik yang ditanam atau dilekatkan secara tetap pada tanah dan/atau perairan pedalaman dan/atau laut. Wolcott (1987, dikutip dalam Mubarak \& Sulastri, 2021), menyatakan bahwa factor yang mempengaruhi nilai tanah dan/atau bangunan adalah ekonomi, sosial, kebijakan pemerintah, dan fisik.

\section{Pendapatan Asli Daerah (PAD)}

Menurut Warsito (2001:128), pendapatan asli daerah merupakan pendapatan yang bersumber dan dipungut sendiri oleh pemerintah daerah. Sumber-sumber PAD terdiri dari pajak daerah, retribusi daerah, laba dari badan usaha milik daerah (BUMD), dan pendapatan asli daerah lainnya yang sah.

\section{METODE}

Penelitian ini menggunakan metode kuantitatif deskriptif. Metode ini lebih mudah menggambarkan objek yang akan diteliti. Objek dari penelitian ini adalah pajak bumi dan bangunan perdesaan dan perkotaan di Kabupaten Situbondo untuk periode tahun 2018-2020. Jenis data yang digunakan dalam penelitian ini berupa data sekunder. Data sekunder diperoleh dari aplikasi pusat data Kabupaten Situbondo yang berkaitan dengan realisasi penerimaan dan target penerimaan PBB-P2, serta realisasi penerimaan PAD. Metode analisis data dilakukan dengan menggunakan rumus sebagai berikut :

\section{Efektivitas PBB-P2}

$$
\text { Efektivitas PBB-P2 }=\frac{\text { Realisasi Penerimaan } P B B-P 2}{\text { Target Penerimaan } P B B-P 2} X 100 \%
$$

Setelah persentase efektivitas diketahui, metode selanjutnya adalah mengukur kriteria nilai efektivitasnya. Semakin besar persentase efektivitasnya maka semakin besar hasil yang akan dicapai. Dibawah ini merupakan pengukuran kriteria efektivitas :

Tabel 1. Kriteria Efektivitas

\begin{tabular}{|c|c|}
\hline Tabel Intepretasi Nilai EFektivitas & Persentase Kriteria \\
\hline$>100 \%$ & Sangat Efektif \\
\hline $90-100 \%$ & Efektif \\
\hline $80-90 \%$ & Cukup Efektif \\
\hline $60-80 \%$ & Kurang EFektif \\
\hline$<60 \%$ & Tidak Efektif \\
\hline
\end{tabular}

Sumber : Departemen Dalam Negeri, Kepmendagri Nomor 690.900.327 Tahun 1996

\section{Kontribusi PBB-P2 terhadap PAD}

Kemudian, untuk mengukur kontribusi pajak bumi dan bangunan perdesaan dan perkotaan (PBB-P2) terhadap pendapatan asli daerah (PAD) yaitu :

$$
\text { Kontribusi PBB-P2 }=\frac{\text { Realisasi Penerimaan } P B B-P 2}{\text { Realisasi Penerimaan } P A D} X 100 \%
$$

Tabel 2. Klasifikasi Kriteria Kontribusi

\begin{tabular}{|c|c|}
\hline Klasifikasi Kriteria Kontribusi & Persentase Kriteria \\
\hline $0,00-10 \%$ & Sangat Kurang \\
\hline $10,10 \%-20 \%$ & Kurang \\
\hline $20,10 \%-30 \%$ & Sedang \\
\hline $30,10 \%-40 \%$ & Cukup Baik \\
\hline $40,10 \%-50 \%$ & Baik \\
\hline Di atas $50 \%$ & Sangat Baik \\
\hline
\end{tabular}

Sumber : Tim Litbang Depdagri-Fisipol UGM 1991 


\section{HASIL DAN PEMBAHASAN}

Target dan Realisasi Penerimaan PBB-P2 Kabupaten Situbondo

Tabel 3. Target dan Realisasi PBB-P2 Kabupaten Situbondo

\begin{tabular}{|c|c|c|}
\hline Tahun & Target & Realisasi \\
\hline 2018 & $\operatorname{Rp~8.257.140.399~}$ & $\operatorname{Rp~3.610.995.504~}$ \\
\hline 2019 & $\operatorname{Rp~8.257.004.550~}$ & $\operatorname{Rp~8.257.004.550~}$ \\
\hline 2020 & $\operatorname{Rp~8.301.202.060~}$ & $\operatorname{Rp~3.288.458.421~}$ \\
\hline
\end{tabular}

Sumber : Aplikasi Pusat Data Kabupaten Situbondo (2020)

Berdasarkan tabel 3 diatas data menunjukan bahwa target penerimaan pajak bumi dan bangunan perdesaan dan perkotaan (PBB-P2) kabupaten Situbondo pada tahun 2018-2020 mengalami kenaikan pada tahun 2018 sebesar Rp 8.257.140.399,00 menjadi Rp 8.301.202.060,00 pada tahun 2020. Realisasi penerimaan pajak bumi dan bangunan perdesaan dan perkotaan (PBB-P2) pada tahun 2018 menunjukan sebesar Rp 3.610.995.504 mengalami kenaikan ke angka Rp 8.257.004.550 pada tahun 2019 lalu pada 2020 mengalami penurunan menjadi Rp 3.288.458.421.

\section{Realisasi PAD Kabupaten Situbondo}

Tabel 4. Realisasi Pendapatan Asli Daerah Kabupaten Situbondo

\begin{tabular}{|c|c|}
\hline Tahun & Realisasi \\
\hline 2018 & Rp 187.287.219.449 \\
\hline 2019 & Rp 204.727.875.621 \\
\hline 2020 & Rp 218.842.796.084 \\
\hline
\end{tabular}

Sumber : Aplikasi Pusat Data Kabupaten Situbondo (2020)

Berdasarkan tabel 4 data menunjukan bahwa realisasi pendapatan asli daerah Kabupaten Situbondo pada tahun 2018 sebesar Rp 187.287.219.449 meningkat signifikan pada tahun 2019 menjadi Rp 204.727.875.621 dan terus mengalami peningkatan hingga tahun 2020 mencapai Rp 218.842.796.084.

\section{Perhitungan Efektivitas Penerimaan PBB P2}

Tabel 5. Tingkat Efektivitas Penerimaan PBB-P2 Kabupaten Situbondo

\begin{tabular}{|c|c|c|c|c|}
\hline Tahun & Target & Realisasi & Efektivitas & Kriteria \\
\hline 2018 & $\operatorname{Rp~} 8.257 .140 .399$ & $\operatorname{Rp~3.610.995.504~}$ & $43,73 \%$ & Tidak efektif \\
\hline 2019 & $\operatorname{Rp~8.257.004.550~}$ & $\operatorname{Rp~8.257.004.550~}$ & $100 \%$ & Efektif \\
\hline 2020 & $\operatorname{Rp~8.301.202.060~}$ & $\operatorname{Rp~3.288.458.421~}$ & $39,61 \%$ & Tidak Efektif \\
\hline
\end{tabular}

Sumber : Data diolah (2021)

Berdasarkan tabel 5 diatas pada tahun 2018 dapat dilihat bahwa realisasi penerimaan PBB-P2 masih belum tercapai sesuai dengan target penerimaan yang sudah ditetapkan. Sesuai dengan Kepmendagri Nomor 690.900.327 Tahun 1996, pada tahun 2018 dengan tingkat efektivitasnya sebesar $43,73 \%$ dan $<60 \%$, maka nilai tersebut termasuk dalam kriteria tidak efektif. Pada tahun 2019 dapat dilihat bahwa target penerimaan sudah tercapai sesuai dengan target penerimaan, dan tingkat efektivitasnya sebesar 100\%, maka dapat dikatakan efektif karena nilainya 90\%-100\%. Pada tahun 2020 target penerimaan PBB-P2 kembali mengalami penurunan yang cukup signifikan dibandingkan dengan tahun sebelumnya. Pada tahun ini 
dengan tingkat efektivitas paling rendah dibandingkan dengan dua tahun sebelumnya. Dengan tingkat efektivitas sebesar 39,61\% kriteria efektivitas tersebut termasuk dalam kriteria tidak efektif karena sesuai dengan Kepmendagri Nomor 690.900.327 Tahun 1996, nilai 39,61\% < $60 \%$. Penerimaan PBB P-2 terhadap Penerimaan Asli Daerah (PAD) di Kabupaten Situbondo mengalami penurunan selama 2 tahun yaitu pada tahun 2018 dan 2020 dan dikatakan tidak efektif, sedangkan pada tahun 2019 penerimaan PBB P-2 dikatakan efektif dan dapat memberikan kontribusi terhadap Pendapatan Asli Daerah (PAD) di Kabupaten Situbondo.

Analisis Kontribusi Pajak Bumi dan Bangunan Perdesaan dan Perkotaan (PBB P2) terhadap Pendapatan Asli Daerah (PAD) Kabupaten Situbondo

Tabel 6. Tingkat Kontribusi PBB-P2 terhadap PAD Kabupaten Situbondo

\begin{tabular}{|c|c|c|c|c|}
\hline Tahun & Realisasi PBB-P2 & Realisasi PAD & Kontribusi & Kriteria \\
\hline 2018 & Rp 3.610.995.504 & Rp 187.287.219.449 & $1,9 \%$ & Sangat Kurang \\
\hline 2019 & Rp 8.257.004.550 & Rp 204.727.875.621 & $4 \%$ & Sangat Kurang \\
\hline 2020 & Rp 3.288.458.421 & Rp 218.842.796.084 & $1,5 \%$ & Sangat Kurang \\
\hline
\end{tabular}

Sumber : Data diolah (2021)

Berdasarkan Tabel 6., diketahui bahwa pada tahun 2018 tingkat kontribusi PBB-P2 dalam pendapatan asli daerah (PAD) sebesar 1,9\%. Kriteria kontribusi ini termasuk dalam kriteria sangat kurang dalam kontribusi PBB-P2 dalam pendapatan asli daerah (PAD). Akan tetapi tingkat kontribusi pada tahun 2018 lebih tinggi dibandingkan tahun 2020. Pada tahun 2019 realisasi penerimaan PBB-P2 mengalami peningkatan dan merupakan tertinggi dalam realisasi penerimaan $\mathrm{PBB}-\mathrm{P} 2$ dibandingkan dengan tahun-tahun yang lainnya. tingkat kontribusi PBB-P2 dalam pendapatan asli daerah (PAD) mengalami kenaikan dibandingkan tahun sebelumnya yaitu menjadi sebesar 4\%. Akan tetapi tingkat kontribusi ini masih termasuk dalam kriteria sangat kurang dalam kontribusi PBB-P2 dalam pendapatan asli daerah (PAD). Pada tahun 2020 realisasi penerimaan PBB-P2 mengalami penurunan dan realisasi penerimaan pendapatan asli daerah (PAD) terus mengalami peningkatan. Namun, tingkat kontribusi PBBP2 dalam pendapatan asli daerah (PAD) kembali mengalami penurunan yaitu menjadi sebesar 1,5\%. Pada tahun ini pun masih termasuk dalam kategori sangat kurang dalam kontribusi PBBP2 dalam pendapatan asli daerah (PAD).

\section{PENUTUP}

\section{Simpulan}

Berdasarkan pada hasil dan pembahasan yang telah dilakukan mengenai efektivitas dan kontribusi PBB-P2 terhadap PAD, maka dapat disimpulkan bahwa tingkat efektivitas dikategorikan dalam kriteria tidak efektif. Walaupun pada tahun 2019 dalam kriteria efektif dikarenakan realisasi penerimaan sesuai dengan target penerimaan yang telah ditentukan. Tingkat kontribusi PBB-P2 terhadap PAD masih dikategorikan dalam kriteria sangat kurang. Meskipun pada tahun tahun 2019 ada peningkatan, namun tidak signifikan kontribusinya terhadap PAD.

\section{Saran}

Berdasarkan hasil penelitian yang telah dilakukan, maka peneliti memberikan saran agar Pemerintah Kabupaten Situbondo diharapkan terus menggali potensi-potensi berupa obyek Pajak Bumi dan Bangunan Pedesaaan dan Perkotaan di Kabupaten Situbondo, dengan begitu akan menambah penerimaan PBB P2 sehingga akan mencapai target yang telah ditetapkan.

\section{DAFTAR PUSTAKA}

Asmandani, V., Pamungkas, T. S., Hidayat, R., Wicaksono, G., Puspita, Y., \& Kusumaningrum, N. D. (2020). Effect Of Using E-Filling On Quality Of Tax Reporting Services In East 
Java: Effect Of Using E-Filling On Quality Of Tax Reporting Services In East Java. Jurnal Mantik, 3(4), 619-625. Retrieved from http://iocscience.org/ejournal/index.php/mantik/article/view/637

Boedijono, B., Wicaksono, G., Puspita, Y., Bidhari, S., Kusumaningrum, N., \& Asmandani, V. (2019). Efektifitas Pengelolaan Dana Desa Untuk Pembangunan Dan Pemberdayaan Masyarakat Desa di Kabupaten Bondowoso. Jurnal Riset Manajemen Dan Bisnis (JRMB) Fakultas Ekonomi UNIAT, 4(1), 9 - 20. https://doi.org/10.36226/jrmb.v4i1.237

Damaiyanti, Ni Putu Dian, dan I putu Ery. Setiawan. (2014). Analisis Efektivitas Dan Kontribusi Penerimaan Pbb Terhadap Pad Kota Denpasar Tahun 2009-2013. E-Jurnal Akuntansi Universitas Udayana. 9.1: 97-105. ISSN: 2302-8556.

Depdagri. (1997). Kepmendagri No.690.900.327 Tahun 1996 tentang Pedoman Penilaian dan Kinerja Keuangan.

Huda, M. N., \& Wicaksono, G. (2021). Analisis Efektivitas Dan Kontribusi Penerimaan Pajak Bumi Dan Bangunan Perdesaan Dan Perkotaan Terhadap Pendapatan Asli Daerah Kota Yogyakarta. Educoretax, 1(4), 284-290. Diambil dari https://jurnalku.org/index.php/educoretax/article/view/108

Mardiasmo. (2009). Akuntansi Sektor Publik Edisi Revisi. Penerbit Andi : Yogyakarta

Mubarak, A. Z., \& Sulastri, H. (2021). Analisis Pengaruh Jalan Bypass Mataram-Gerung Terhadap Nilai Tanah Di Lombok Barat. Journal of Law, Administration, and Social Science, 1(1), 40-46. Diambil dari https://jurnalku.org/index.php/jolas/article/view/87

Mustofa, S. M. H. W., \& Usman, F. (2021). Perubahan Nilai Jual Objek Pajak Sektor Perkebunan Tahun Pajak 2020 Terhadap Tahun Pajak 2019: (Studi Kasus Di Kantor Pelayanan Pajak Pratama Salatiga). Educoretax, 1(3), 230-239. Diambil dari https://jurnalku.org/index.php/educoretax/article/view/43

Pusda.Situbondo.go.id. (n.d.). Tabel : Ketetapan dan Penerimaan Pajak Bumi dan Bangunan.

Pusda.situbondokab.go.id. (n.d.). Tabel : Realisasi Pendapatan.

Soekanto, S. (2012). Sosiologi Suatu Pengantar. Jakarta: Rajawali Pers.

Suparmono. (2010). Perpajakan Indonesia. Mekanisme dan Perhitungan. Edisi Revisi 2009. Yogyakarta: Cv. Andi Offset.

Guritno, T. (1997). Kamus Ekonomi. Yogyakarta: Gadjah Mada University Press.

Uundang-Undang Republik Indonesia Nomor 28 Tahun 2007 tentang Ketentuan Umum dan Tata Cara Perpajakan.

Undang-Undang Republik Indonesia Nomor 28 Tahun 2009 tentang Pajak Daerah dan Retribusi Daerah

Waluyo. (2013). Perpajakan Indonesia. Jakarta: Salemba Empat

Wardani, Raudhatun dan Wida, Fadhlia. (2017). Analisis Efektivitas Penerimaan Pajak Bumi Dan Bangunan Perdesaan Dan Perkotaan Dan Kontribusinya Terhadap Pendapatan Asli Daerah Di Kabupaten Aceh Besar. Jurnal Ilmiah Mahasiswa Ekonomi Akuntansi (JIMEKA) Vol. 2, No. 3, Halaman 10-17 E-ISSN 2581-1002

Warsito. (2001). Pendapatan Asli Daerah. Jakarta : PT. Rajawali Grafindo Persada

Wicaksono, G., \& Pamungkas, T. S. (2017). Analisis Efektivitas dan Kontribusi Pajak Bumi dan Bangunan Perdesaan dan Perkotaan (PBB P2) terhadap Pendapatan Asli Daerah (PAD) Kabupaten Jember. Jurnal Stie Semarang (Edisi Elektronik), 9(1), 67-76. 